Review

\title{
Recent Advances in the Plasma-Assisted Synthesis of Zinc Oxide Nanoparticles
}

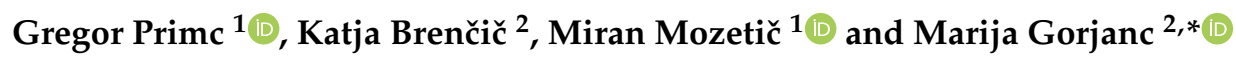 \\ 1 Department of Surface Engineering, Jozef Stefan Institute, Jamova cesta 39, 1000 Ljubljana, Slovenia; \\ gregor.primc@ijs.si (G.P.); miran.mozetic@guest.arnes.si (M.M.) \\ 2 Department of Textiles, Graphic Arts and Design, Faculty of Natural Sciences and Engineering, University of \\ Ljubljana, Aškerčeva 12, 1000 Ljubljana, Slovenia; katja.brencic@ntf.uni-lj.si \\ * Correspondence: marija.gorjanc@ntf.uni-lj.si
}

Citation: Primc, G.; Brenčič, K.; Mozetič, M.; Gorjanc, M. Recent Advances in the Plasma-Assisted Synthesis of Zinc Oxide Nanoparticles. Nanomaterials 2021, 11, 1191. https://doi.org/10.3390/ nano11051191

Academic Editors: Fabien Grasset and Alessandro De Giacomo

Received: 22 March 2021

Accepted: 27 April 2021

Published: 30 April 2021

Publisher's Note: MDPI stays neutral with regard to jurisdictional claims in published maps and institutional affiliations.

Copyright: (c) 2021 by the authors. Licensee MDPI, Basel, Switzerland. This article is an open access article distributed under the terms and conditions of the Creative Commons Attribution (CC BY) license (https:// creativecommons.org/licenses/by/ $4.0 /)$.

\begin{abstract}
An overview of recent work on the low-temperature plasma-assisted synthesis of zinc oxide $(\mathrm{ZnO})$ nanoparticles is presented and interpreted in terms of gas-phase and surface reactions with illustrated examples. The thermodynamical nonequilibrium conditions allow the formation of chemically reactive species with a potential energy of several $\mathrm{eV}$, which readily interact with the $\mathrm{Zn}$ precursors and initiate reactions leading to the formation of nanoparticles or nanowires. The highquality nanowires were synthesized from $\mathrm{Zn}$ powders only upon interaction with moderately ionized plasma in a narrow range of plasma parameters. This technique is promising for the synthesis of large quantities of nanowires with aspect ratios well above 10, but the exact range of parameters remains to be determined. Apart from the ex situ techniques, the $\mathrm{ZnO}$ nanoparticles can be synthesized by depositing a film of precursors (often $\mathrm{Zn}$ salts or $\mathrm{Zn}$-containing organometallic compounds) and exposing them to oxygen plasma. This technique is useful for the synthesis of well-adherent $\mathrm{ZnO}$ nanoparticles on heat-sensitive objects but requires further scientific validation as it often leads to the formation of a semicontinuous $\mathrm{ZnO}$ film rather than nanoparticles. Both low-pressure and atmospheric plasmas are useful in converting the precursor film into $\mathrm{ZnO}$ nanoparticles despite completely different mechanisms.
\end{abstract}

Keywords: plasma; synthesis; zinc oxide; nanoparticles

\section{Introduction}

Metal oxide nanoparticles have attracted the attention of both the scientific community and users as their properties often differ significantly from those of bulk materials. Perhaps the most studied are titanium dioxide nanoparticles, followed by silica and zinc oxide nanoparticles (nano- $\mathrm{ZnO}$ ) [1,2]. Nano- $\mathrm{ZnO}$ has multifunctional physiochemical properties, high photostability and a broad absorption band [3]. It is also considered to be nontoxic and it is stable at high temperatures [4]. Otherwise, $\mathrm{ZnO}$ has multifunctional properties such as photocatalytic self-cleaning and antimicrobial activity, ultraviolet (UV) protection, flame retardancy, thermal insulation, moisture management and electrical conductivity [5]. These properties enable $\mathrm{ZnO}$ to be used for development of superhydrophobic, antibacterial, antistatic, UV-protective and self-cleaning products, UV light sources, gas sensors, transparent electrodes in solar cells, spintronics devices and biosensors [5-9]. Numerous methods have been invented for the synthesis of $\mathrm{ZnO}$ nanoparticles, including wet-chemical methods, combustion of $\mathrm{Zn}$-containing precursors, laser ablation, hydrothermal and electrochemical methods, and chemical vapour deposition [3-5,7-18]. Depending on the synthesis parameters, a variety of morphological shapes have been reported [13]. These include simple spherical particles, three-dimensional particles with more complex shapes, nanorods and nanowires. The latter can have aspect ratios greater than 10 or even greater than 100 [14-23]. The vast majority of $\mathrm{ZnO}$ nanoparticles have 
more spherical shapes since such a morphology represents the minimum surface energy and is the most thermodynamically favourable.

Plasma techniques for the synthesis of $\mathrm{ZnO}$ nanoparticles are becoming increasingly important as the thermodynamic nonequilibrium conditions allow the synthesis of nanoparticles with interesting morphological properties that cannot be achieved by other techniques. In addition, nonequilibrium conditions often allow chemical reactions to occur at a lower temperature than their thermal equilibrium counterparts, making them of interest for any application where the substrate cannot tolerate heating to high temperatures. An alternative to nonequilibrium plasma is the application of powerful discharges, which enable sustaining plasma at high temperatures. In the case of such hot plasmas, the chemical reactions leading to formation of nanoparticles are predominantly due to the high temperatures of both the gas and the solid particles. This paper reviews some recent work on the deposition of $\mathrm{ZnO}$ nanoparticles by plasma methods and explains the mechanisms, highlighting both the advantages and disadvantages of particular embodiments. Table 1 summarizes the plasma-assisted methods for synthesizing $\mathrm{ZnO}$ nanoparticles. 
Table 1. Summary of plasma-assisted methods for synthesizing $\mathrm{ZnO}$ nanoparticles.

\begin{tabular}{|c|c|c|c|c|c|c|c|c|c|}
\hline \multicolumn{2}{|c|}{ Plasma System/Discharge Type } & $\begin{array}{l}\text { Discharge } \\
\text { Parameters }\end{array}$ & Gas & Zn-Precursor & $\begin{array}{l}\text { Substrate for } \\
\text { Deposition }\end{array}$ & ZnO Morphology & Size & Other ZnO Properties & Ref. No. \\
\hline \multirow{8}{*}{ Low-pressure } & $\begin{array}{l}\text { Radiofrequency (RF) } \\
\text { inductively coupled } \\
\text { thermal plasma }\end{array}$ & $\begin{array}{c}\mathrm{p}=350,650 \text { and } 700 \\
\text { Torr } \\
\mathrm{P}=28-31 \mathrm{~kW} \\
\mathrm{f}=1-3 \mathrm{MHz}\end{array}$ & $\begin{array}{c}\text { Ar as } \\
\text { carrier gas }\end{array}$ & $\mathrm{ZnO}$ powder & $\mathrm{N} / \mathrm{A}$ & $\begin{array}{l}\text { polygonal at } \\
350 \text { Torr, round at } \\
650 \text { Torr, flower-like } \\
\text { with hexagonal } \\
\text { nanorods at } 700 \text { Torr }\end{array}$ & $\begin{array}{c}60-70 \mathrm{~nm} \\
\text { at } 350 \text { Torr, } 30-50 \mathrm{~nm} \\
\text { at } 650 \text { Torr, } \\
200-500 \mathrm{~nm} \text { in } \\
\text { diameter with } \\
3-6 \mathrm{~nm} \text { rods at } \\
700 \text { Torr }\end{array}$ & $\begin{array}{l}\text { good crystal quality and } \\
\text { optical property }\end{array}$ & [24] \\
\hline & $\begin{array}{l}\text { RF inductively coupled } \\
\text { plasma }\end{array}$ & $\begin{array}{c}\mathrm{p}=1 \mathrm{~Pa} \\
\mathrm{P}=100 \mathrm{~W} \\
\mathrm{f}=13.56 \mathrm{MHz} \\
\mathrm{t}=15 \mathrm{~min}\end{array}$ & $\mathrm{Ar} / \mathrm{O}_{2}$ & $\mathrm{ZnCl}_{2}$ powder & Si wafers & $\begin{array}{l}\text { cone-sharp vertically } \\
\text { grown }\end{array}$ & N/A & hexagonal $\mathrm{ZnO}$ structure & [25] \\
\hline & RF plasma torch & $\begin{array}{l}\mathrm{p}=150 \text { Torr } \\
\mathrm{P}=30 \mathrm{~kW} \\
\mathrm{f}=3.5 \mathrm{MHz}\end{array}$ & $\begin{array}{c}\mathrm{Ar} / \mathrm{O}_{2} \text { for } \mathrm{ZnO} \\
\mathrm{Ar} / \text { air for N-doped } \\
\mathrm{ZnO}\end{array}$ & $\begin{array}{l}\text { Zn powder } \\
100-180 \mu \mathrm{m}\end{array}$ & glass & spherical & $\begin{array}{c}\text { Zn powder feed } \\
\text { rates enlarge particle } \\
\text { size }\end{array}$ & $\begin{array}{l}\text { hexagonal } \mathrm{ZnO} \text { wurtzite } \\
\text { structure }\end{array}$ & [26] \\
\hline & $\begin{array}{l}\text { RF plasma enhanced atomic } \\
\text { layer deposition }\end{array}$ & $\begin{array}{c}\mathrm{p}=5 \times 10^{-4} \mathrm{mbar} \\
\mathrm{P}=200 \mathrm{~W} \\
\mathrm{f}=13.56 \mathrm{MHz} \\
\mathrm{T}_{\text {deposition }}= \\
60-220^{\circ} \mathrm{C} \\
\mathrm{t}=50-150 \mathrm{~ms}\end{array}$ & $\mathrm{O}_{2}$ & $\begin{array}{l}\text { bis-3-(N,N- } \\
\text { dimethylamino)propyl } \\
\text { zinc }\end{array}$ & $\begin{array}{l}\text { Si wafers, } \\
\text { polyethylene } \\
\text { terephthalate }\end{array}$ & N/A & N/A & $\begin{array}{l}\mathrm{ZnO} \text { thin, uniform, } \\
\text { smooth, stoichiometric, } \\
\text { and highly transparent } \\
\text { films }\end{array}$ & [27] \\
\hline & MW reactor & $\begin{array}{c}\text { optimal parameters: } \\
p=30 \mathrm{mbar} \\
P=60 \mathrm{~W} \\
t=90 \mathrm{~min}\end{array}$ & $\begin{array}{l}80 \% \mathrm{Ar} / \\
20 \% \mathrm{O}_{2}\end{array}$ & $\begin{array}{c}\mathrm{Ar} / \mathrm{Zn}\left(\mathrm{CH}_{3}\right)_{2} \\
\mathrm{c}_{\mathrm{Zn}(\mathrm{CH} 3)^{2}}=1061 \mathrm{ppm}\end{array}$ & TEM grids & spherical & $4.2-5.9 \mathrm{~nm}$ & $\begin{array}{l}\text { band gap } \\
\text { at } 3.28 \mathrm{eV}\end{array}$ & [23] \\
\hline & MW magnetron & $\mathrm{t}=1$ and $4 \mathrm{~s}$ & Air & $\begin{array}{l}\text { Zn swarf collected } \\
\text { from the drilling } \\
\text { of the } \mathrm{Zn} \text { ingot }\end{array}$ & $\begin{array}{l}\text { Al foil, glass, paper, } \\
\text { microfiber, } \\
\text { polycarbonate film, } \\
\text { paraffin wax }\end{array}$ & $\begin{array}{c}\text { round at } 1 \mathrm{~s}, \\
\text { nanowires at } 4 \mathrm{~s}\end{array}$ & $\begin{array}{l}\phi 50 \mathrm{~nm} \text { at } 1 \mathrm{~s}, \\
\phi 65 \mathrm{~nm} \text { at } 4 \mathrm{~s}\end{array}$ & $\begin{array}{l}\text { wurtzite structure of } \\
\text { ZnO, good } \\
\text { crystallographic, quality } \\
\text { of nanowires }\end{array}$ & [28] \\
\hline & $\begin{array}{c}\text { Pulsed high-current coaxial } \\
\text { magnetoplasma accelerator } \\
\text { plasma jet }\end{array}$ & $\begin{array}{c}\text { Pulsed mode } \\
\text { with: } E_{\text {pulse }}=27.7 \mathrm{~kJ} \\
\mathrm{I}=10^{5} \mathrm{~A} \\
\mathrm{t}=1 \mathrm{~ms}\end{array}$ & $\mathrm{O}_{2}$ & Metallic Zn electrode & $\begin{array}{l}\text { Wall of reactor } \\
\text { chamber }\end{array}$ & Hexagonal & Size $150-350 \mathrm{~nm}$ & $\begin{array}{c}\text { Production of } 10 \mathrm{~g} \mathrm{ZnO} \\
\text { per } 1 \text { cycle, } \\
\text { single-crystalline } \\
\text { structure }\end{array}$ & [29] \\
\hline & $\begin{array}{l}\text { Coaxial magnetoplasma } \\
\text { accelerator with zinc } \\
\text { electrodes }\end{array}$ & $\begin{array}{l}\mathrm{U}=3.4 \mathrm{kV} \\
\mathrm{I}=100 \mathrm{kA} \\
\mathrm{W}=27.7 \mathrm{~kJ}\end{array}$ & $80 \% \mathrm{O}_{2}$ & $\begin{array}{l}\text { Zn electrode in } \\
\text { plasma }\end{array}$ & SPS-ceramics & $\begin{array}{c}\text { round and } \\
\text { hexagonal shape }\end{array}$ & $10-150 \mathrm{~nm}$ & $\begin{array}{c}\text { high purity, } \\
\text { single-crystalline } \\
\text { hexagonal } \mathrm{ZnO}\end{array}$ & [7] \\
\hline
\end{tabular}


Table 1. Cont.

\begin{tabular}{|c|c|c|c|c|c|c|c|c|c|}
\hline \multicolumn{2}{|c|}{ Plasma System/Discharge Type } & $\begin{array}{l}\text { Discharge } \\
\text { Parameters }\end{array}$ & Gas & Zn-Precursor & $\begin{array}{l}\text { Substrate for } \\
\text { Deposition }\end{array}$ & ZnO Morphology & Size & Other $\mathrm{ZnO}$ Properties & Ref. No. \\
\hline \multirow{9}{*}{$\begin{array}{l}\text { Atmospheric- } \\
\text { pressure }\end{array}$} & $\begin{array}{c}\text { Alternative/direct } \\
\text { (AC/DC) current dielectric } \\
\text { barrier discharge (DBD) }\end{array}$ & $\begin{array}{c}\mathrm{U}=16.7 \mathrm{kV} \\
\mathrm{f}=5 \mathrm{kHz} \\
\mathrm{t}=30-600 \mathrm{~s} \\
\text { (optimum } 240 \mathrm{~s} \text { ) }\end{array}$ & Air & Zn plate & Zn plate & $\begin{array}{c}\text { porous } \mathrm{ZnO} \\
\text { nanosheet-assembly } \\
\text { film after calcination } \\
\text { at } 250^{\circ} \mathrm{C} \text { for } 1 \mathrm{~h}\end{array}$ & $30-50 \mathrm{~nm}$ & $\begin{array}{c}\text { single-crystalline } \\
\text { structure, band gap of } \\
3.24 \mathrm{eV}, 90 \% \mathrm{UV} \\
\text { absorption }\end{array}$ & {$[30]$} \\
\hline & AC (pulse) plasma jet & $\begin{array}{c}\mathrm{U}=511 \mathrm{~V} \\
\mathrm{I}=125 \mathrm{~mA} \\
\mathrm{E}=1.050 \mathrm{~J} / \mathrm{s} \\
\mathrm{t}=1 \mathrm{~h} \\
\mathrm{~d}=10 \mathrm{~mm}\end{array}$ & Air & $\begin{array}{l}\text { Zn nitrate }(\mathrm{ZN}) \text {, } \\
\text { Zn chloride }(\mathrm{ZC}) \text {, } \\
\text { Zn sulphate (ZS) }\end{array}$ & N/A & $\begin{array}{c}\text { rods, pillar and, } \\
\text { flower-like for ZN, } \\
\text { flower-like and rods } \\
\text { for ZC, layered and } \\
\text { aggregated } \\
\text { structures for ZS }\end{array}$ & $\begin{array}{l}\text { from } 400 \times 200 \text { to } \\
1600 \times 600 \mathrm{~nm} \text {, or } \phi \\
500 \mathrm{~nm}\end{array}$ & $\begin{array}{l}\text { good crystallinity, high } \\
\text { purity and fewer } \\
\text { structural defects }\end{array}$ & [31] \\
\hline & $\begin{array}{l}\text { AC (sinusoidal) dielectric } \\
\text { barrier discharge plasma }\end{array}$ & $\begin{array}{c}\mathrm{p}=1 \mathrm{bar} \\
\mathrm{U}=15 \mathrm{kV} V_{\mathrm{pp}} \\
\mathrm{f}=29 \mathrm{kHz}\end{array}$ & He & $\begin{array}{l}0.5,1 \text { and } 2 \mathrm{M} \text { zinc } \\
\text { acetate aqu. }\end{array}$ & Si wafer & spherical & $90-150 \mathrm{~nm}$ & $\begin{array}{l}\text { nanocomposites of } \\
\text { crystalline nanoparticles } \\
\text { and amorphous matrix }\end{array}$ & [32] \\
\hline & DC pulsed plasma jet & $\begin{aligned} \mathrm{U} & =275 \mathrm{~V} \\
\mathrm{t} & =30 \mathrm{~s}\end{aligned}$ & $\mathrm{~N}_{2}$ & $\begin{array}{l}10 \mathrm{mM} \text { zinc acetate } \\
\text { spin coated on } \\
\text { substrate }\end{array}$ & $\begin{array}{l}\text { F-doped tin oxide } \\
\text { glass substrates }\end{array}$ & $\begin{array}{l}\text { polygonal } \mathrm{Pt} / \mathrm{ZnO} \\
\text { composite } \\
\text { nanoparticles }\end{array}$ & N/A & $\begin{array}{l}\text { catalytic activities of } \\
\text { Pt/ZnO, low charge } \\
\text { transfer resistance, high } \\
\text { exchange current density }\end{array}$ & [33] \\
\hline & DC plasma torch & $\mathrm{P}_{\text {nominal }}=55 \mathrm{~kW}$ & $\begin{array}{l}\text { Ar as primary and } \\
\mathrm{H}_{2} \text { as secondary gas }\end{array}$ & $\begin{array}{l}0.2 \mathrm{M} \text { and } 0.4 \mathrm{M} \\
\mathrm{Zn} \text { acetate }(\mathrm{ZA}), \\
\mathrm{Zn} \text { nitrate }(\mathrm{ZN})\end{array}$ & Al plates & $\begin{array}{l}\text { nanowires, nanorods } \\
\text { for ZA, porous } \\
\text { microstructures, } \\
\text { nanorods and } \\
\text { shell-like particles } \\
\text { for ZN }\end{array}$ & $\mathrm{N} / \mathrm{A}$ & $\begin{array}{l}\text { well crystalline wurtzite } \\
\mathrm{ZnO} \text {, fair photocatalytic } \\
\text { properties }\end{array}$ & [34] \\
\hline & DC plasma torch & $\mathrm{P}=70 \mathrm{~kW}$ & $\begin{array}{l}\mathrm{N}_{2} / \mathrm{Ar}(1: 1) \text { and } \mathrm{N}_{2} \\
\text { as carrier gases }\end{array}$ & $50 \mathrm{ppm} Z \mathrm{Zn}$ powders & $\begin{array}{l}\text { None (powder } \\
\text { collector) }\end{array}$ & $\begin{array}{l}\text { with } \mathrm{N}_{2} / \text { Ar rod-like, } \\
\text { with } \mathrm{N}_{2} \text { spherical }\end{array}$ & $\begin{array}{l}100-200 \mathrm{~nm} \text { with } \\
\mathrm{N}_{2} / \mathrm{Ar}, 30 \mathrm{~nm} \\
\text { with } \mathrm{N}_{2}\end{array}$ & $\begin{array}{l}\text { high purity, high crystal } \\
\text { quality of the ZnO } \\
\text { nanopowders, wurtzite } \\
\text { phase ZnO }\end{array}$ & [35] \\
\hline & Plasma jet & $\begin{array}{l}\mathrm{p}=1 \mathrm{bar} \\
\mathrm{I}=40 \mathrm{~mA} \\
\mathrm{t}=10 \mathrm{~min} \\
\mathrm{~d}=5 \mathrm{~mm}\end{array}$ & Air & $\begin{array}{c}0.05 \mathrm{M} \text { zinc nitrate } \\
\text { aqu. }\end{array}$ & $\begin{array}{l}\text { Particles formed in } \\
\text { liquid }\end{array}$ & $\begin{array}{l}\text { Spherical and } \\
\text { cylindrical }\end{array}$ & 2 and $3 \mathrm{~nm}$ & $\begin{array}{l}\text { a number of particles had } \\
\text { a hexagonal shape }\end{array}$ & [3] \\
\hline & Plasma torch & $\begin{array}{l}\mathrm{p}=86.1 \mathrm{kPa} \\
\mathrm{P}=15 \mathrm{~kW}\end{array}$ & $\begin{array}{c}\text { Ar as } \\
\text { carrier gas }\end{array}$ & $\begin{array}{l}\text { Zn nitrate powder } \\
50 \mu \mathrm{m}\end{array}$ & N/A & spherical & $\sim 57 \mathrm{~nm}$ & $\begin{array}{l}\text { hexagonal wurtzite } \\
\text { structure, UV emission } \\
\text { band at } 383 \mathrm{~nm} \text {, excellent } \\
\text { electric properties, } 80 \% \\
\text { optically transmissive, } \\
\text { photocatalytic properties }\end{array}$ & {$[36]$} \\
\hline & $\begin{array}{c}\text { Microwave (MW) } \\
\text { waveguide plasma }\end{array}$ & $\mathrm{f}=2.45 \mathrm{GHz}$ & $\begin{array}{c}\text { High-pure air (HPA), } \\
\text { compressed air (CA), } \\
\mathrm{O}_{2} \text {, and } 20 \% \\
\mathrm{O}_{2} / 80 \% \mathrm{~N}_{2}\end{array}$ & $10 \mu \mathrm{m} \mathrm{Zn} \mathrm{powder}$ & Wall of quartz tube & $\begin{array}{c}\text { nanowires and } \\
\text { terapods with HPA, } \\
\text { nanorods with CA } \\
\text { and } \mathrm{O}_{2} \text {, tetrapods } \\
\text { with } \mathrm{O}_{2} / \mathrm{N}_{2}\end{array}$ & $\begin{array}{c}\text { diameter 29.7-626.5, } \\
\text { length } \\
256.5-5835.0 \mathrm{~nm}\end{array}$ & $\begin{array}{l}\text { single crystal ZnO } \\
\text { nanowires of a hexagonal } \\
\text { crystal structure, UV } \\
\text { absorption band near } \\
370 \mathrm{~nm}\end{array}$ & [37] \\
\hline
\end{tabular}




\section{Plasma Methods for Synthesizing ZnO Nanoparticles}

\subsection{Low-Pressure Plasmas}

Low-pressure plasmas are popular for the treatment of solid materials due to the uniformity of plasma parameters over a rather large volume. The uniformity is due to the lack of the gas-phase collisions that lead to the loss of reactive species by neutralization of charged particles, the association of neutral radicals to stable molecules and relaxation of metastables in superelastic collisions [38]. Such plasmas can be sustained by various discharges, but the most popular are electrodeless discharges. The microwave discharges are particularly useful for the synthesis of zinc oxide nanoparticles. Plasma is sustained in a dielectric tube, which is mounted into a microwave cavity. A typical configuration is shown in Figure 1a. The dielectric tube is hermetical tightly mounted between the feeding and collecting chambers. The system is pumped with a suitable vacuum pump that enables evacuation as well as the removal of gaseous reaction products. The gas flow is in the direction from the feeding to the collection chamber. The dielectric tube is mounted into a metallic cavity which is powered with a microwave source. The standing waves in the cavity ignite the discharge in the dielectric tube. As soon as the plasma is ignited, the gas within the dielectric tube becomes conductive, so the skin effect prevents propagation of the electromagnetic field inside the plasma. The field is thus concentrated to the sheath between plasma and the dielectric tube, so it has a high amplitude, which is beneficial for the acceleration of electrons to a high kinetic energy. The fast electrons accelerated within the sheath collide with slow plasma electrons and transfer their energy in elastic collisions. The electrons inside the plasma thus assume a large temperature, often a few 10,000 K. Such electrons are capable of ionizing and dissociating collisions with the precursors. The precursors and reactive gases are fed continuously into the system. The nanoparticles are formed in the plasma volume and accumulate in the collection chamber. The pumping should be configured in such a way as to prevent significant removal of as-synthesized particles.

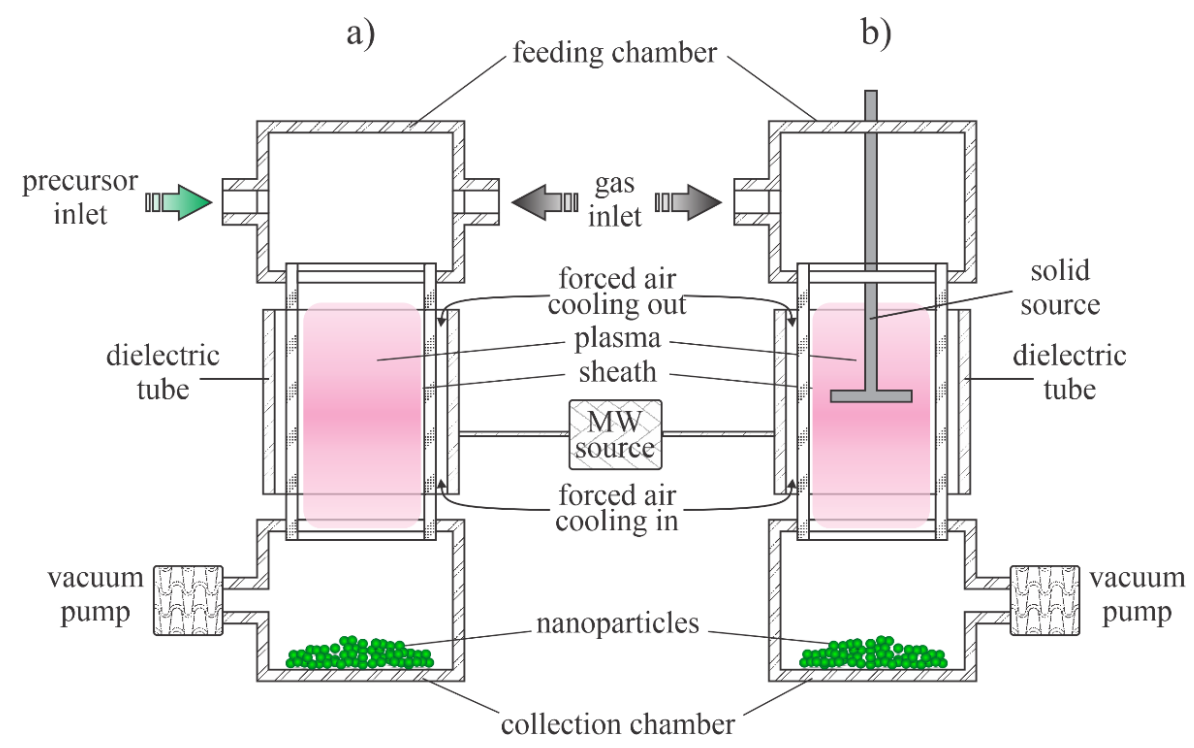

Figure 1. Schematic of the low-pressure microwave plasma system for nanoparticle synthesis: (a) with organometallic gaseous or powder precursor; (b) with solid precursor placed into the plasma reactor.

The configuration in Figure 1a is useful in cases of gaseous or powder precursors fed continuously into the plasma reactor. Other authors employed precursors placed directly in the plasma. Such a configuration is presented in Figure 1b. Any metallic object placed into the microwave field will be heated due to surface currents in electrically conductive 
materials stimulated by the oscillating electromagnetic field, so the precursor will melt and evaporate when using the configuration of Figure $1 \mathrm{~b}$.

Probably the most straightforward technique for synthesizing any metal oxide nanoparticle in the gas phase is to heat precursors in an oxidative atmosphere. The precursors (often $\left.\mathrm{Zn}\left(\mathrm{CH}_{3}\right)_{2}\right)$ are fed into a burner along with oxygen or water vapour. However, this technique may not lead to the best quality $\mathrm{ZnO}$ nanoparticles. To overcome the problem of optimal oxidation of $\mathrm{Zn}\left(\mathrm{CH}_{3}\right)_{2}$ precursors, Kleinwechter et al. [23] proposed using a microwave-driven plasma reactor, as shown schematically in Figure 1a. A typical discharge power was $60 \mathrm{~W}$ and a typical pressure was $30 \mathrm{mbar}$, and plasma was sustained in a mixture of $20 \mathrm{vol} \% \mathrm{O}_{2}$ and $80 \mathrm{vol} \%$ Ar. The concentration of $\mathrm{Zn}\left(\mathrm{CH}_{3}\right)_{2}$ was varied between 700 and $1800 \mathrm{ppm}$. The nanoparticles were rather spherical with diameters of several $\mathrm{nm}$ and did not agglomerate. The particle diameter increased monotonically with the increasing concentration of the precursor. In the second experiment, the pressure was varied at a fixed precursor concentration, and the authors found an increasing particle diameter with increasing pressure. When the discharge power was varied, and other parameters were fixed, the nanoparticle dimension decreased with increasing discharge power. The authors found microwave plasma synthesis to be a suitable method to overcome the difficulties encountered in particle formation in a chemically heated rector-namely, instead of individual nanoparticles, a thin greyish film formed that strongly adhered to the substrate when the same gas mixtures were used to synthesize nanoparticles in a classical oven. According to the authors, the plasma system used by Kleinwechter et al. [23] enabled the choice between chemical and physical energy and a better understanding of particle formation processes. No details of the chemical reactions upon plasma conditions were given in [23], but there are numerous papers on microwave plasma behaviour in the range of pressures around 10 bar. A relatively complete insight into the gas-phase reactions in $\mathrm{Ar}-\mathrm{O}_{2}$ plasmas sustained by microwave discharges was provided by Kutasi et al. [39]. The work presents scientifically sound simulations based on experimental observations. Indeed, current characterization techniques only allow the quantitative measurement of a few types of plasma species. Kutasi et al. [39] explained different gas-phase and surface reactions and concluded that the $\mathrm{Ar}-\mathrm{O}_{2}$ mixtures in microwave plasma are always rich in $\mathrm{O}$ atoms. Dissociation of oxygen molecules occurs both at collisions of electrons from the high-energy tail of their distribution function as well as at collisions with $\mathrm{Ar}^{*}$ metastables. The potential barrier for the oxidation of $\mathrm{Zn}\left(\mathrm{CH}_{3}\right)_{2}$ molecules with $\mathrm{O}$ atoms is much lower than for $\mathrm{O}_{2}$. The reaction efficiency depends on the concentration of two reactants. Kleinwechter et al. [23] reported the concentration of $\mathrm{Zn}\left(\mathrm{CH}_{3}\right)_{2}$ to be around $1000 \mathrm{ppm}$, which is much less than the concentration of $\mathrm{O}$ atoms, which is reported to be well over 10,000 ppm. Thus, the oxidation is efficient. This is because there are numerous channels for the dissociation of $\mathrm{Zn}\left(\mathrm{CH}_{3}\right)_{2}$, and the electron energy required to subtract an $\mathrm{H}$ atom from the molecules is less than the dissociation energy of $\mathrm{O}_{2}$ molecules. The $\mathrm{Zn}\left(\mathrm{CH}_{3}\right)_{2}$ molecules form different radicals, and the oligomerization probably takes place at a pressure of several 10 mbar $[3,4]$. The clusters are heated under plasma conditions by heterogeneous surface reactions [40] so that their temperature remains high while they are in the plasma. This high temperature favours the complete oxidation of the clusters and thus the formation of highly crystalline $\mathrm{ZnO}$. The clusters assume the floating potential the same as any other object immersed in a gaseous nonequilibrium plasma. A negative charge develops on the clusters while they are in the plasma, and the retarding electrostatic force suppresses agglomeration. As disclosed by Kleinwechter et al. [23], plasma synthesis ensures the high quality of $\mathrm{ZnO}$ nanoparticles and prevents their agglomeration.

A schematic of plasma synthesis of $\mathrm{ZnO}$ nanoparticles using $\mathrm{Zn}$-containing organic precursors is shown in Figure 2. The organometallic precursor forms radicals either by electron impact dissociation or quenching of $\mathrm{Ar}^{*}$ metastables. The radicals are further split to form $\mathrm{Zn}$ atoms, which can also be excited or even ionized. Simultaneously, oxidation takes place, leading to the formation of molecules, such as $\mathrm{OH}, \mathrm{H}_{2} \mathrm{O}$, and $\mathrm{CO}$, which are then associated with other atoms to form stable molecules (carbon dioxide and water). Rad- 
icals tend to associate with each other and form initial clusters. This effect was elaborated for other precursors (see the recent paper [41] and references therein). The initial small clusters adsorb radicals, and zinc atoms also condense on the surface, so the clusters grow. Simultaneously, they become negatively charged due to the attachment of slow plasma electrons. The negatively charged clusters attract positively charged species, causing further growth. Hydrogen and carbon, which are present in radicals and early stage clusters, readily interact with oxygen radicals (particularly $\mathrm{O}$ atoms that are in abundance in $\mathrm{Ar}-\mathrm{O}_{2}$ plasma [39]) so almost pure $\mathrm{ZnO}$ is formed with a prolonged residence time. All surface reactions are exothermic. Hence, the cluster and nanoparticles' temperature is well above the ambient temperature as long as they remain in plasma.

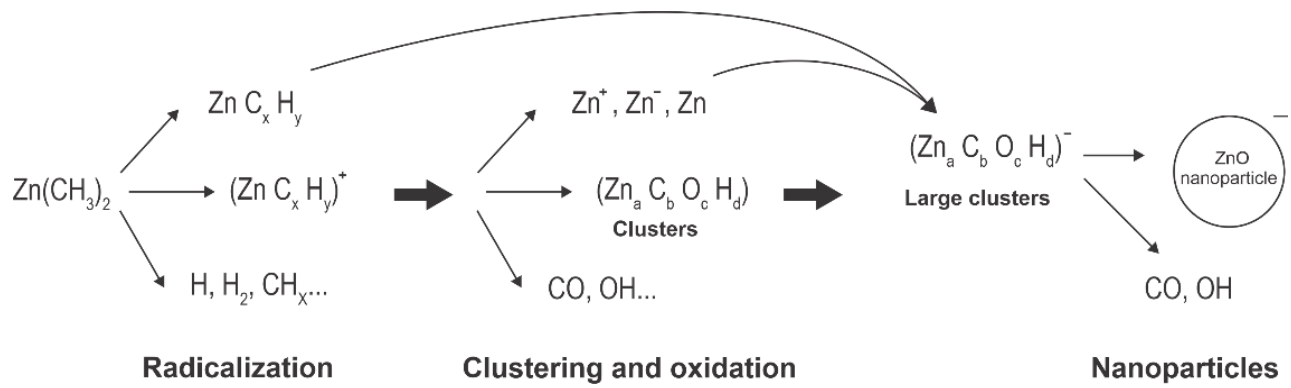

Figure 2. Schematic depiction of the complex reactions that can occur in gas mixtures of argon, oxygen and organometallic gasses under plasma conditions.

Metallic vapour is also useful for synthesizing metal oxide nanoparticles. Rapid synthesis of $\mathrm{ZnO}$ nanoparticles using microwave plasma was reported by Subannajui [28]. Zinc swarf was placed in the centre of an alumina container and brought near to the microwave radiation source, as shown schematically in Figure $1 \mathrm{~b}$. The microwaves induced an internal potential that produced a very high field at the sharp peaks and edges of the $\mathrm{Zn}$ swarf. As a result, dense and hot plasma formed over the swarf, causing the material to melt and vaporize. The metal vapours condensed and oxidized in the region of the less intense plasma and the material was deposited on the surfaces facing the plasma in the form of $\mathrm{ZnO}$ nanoparticles. Even one second of such an aggressive treatment enabled deposition of some nanomaterials, but about $4 \mathrm{~s}$ was found to be the optimal treatment time for the growth of nanowires with a large aspect ratio. The early stage $\mathrm{ZnO}$ nanowires did not appear in the form of rods but as round and irregular long-ellipsoidal nanoparticles. Plasma treatment of a few seconds allowed the synthesis of nanowires with a rather uniform diameter of about $65 \mathrm{~nm}$, but longer treatment times led to the deposition of films containing different shapes of $\mathrm{ZnO}$. Subannajui [28] proposed a four-step mechanism. First, Zn atoms were sputtered or evaporated out of the swarf, and then they were oxidized, deposited and agglomerated on the substrate without catalysts. In the second step, a large number of $\mathrm{ZnO}$ nuclei were generated, and the $\mathrm{Zn}$ atoms were further oxidized and developed into larger $\mathrm{ZnO}$ nanoparticles. In the third step, the $\mathrm{ZnO}$ nanoparticles were stretched and became irregular long ellipsoidal particles. These long ellipsoidal particles tended to organize into the most stable state and become $\mathrm{ZnO}$ nanowires in the last step. A small peak corresponding to metallic $\mathrm{Zn}$ in the X-ray diffraction (XRD) spectrum indicated incomplete oxidation, but the oxide was found in the wurtzite structure of the $\mathrm{ZnO}$ nanowires. UV-Vis absorption spectroscopy showed good absorption in the UV region with a peak at about $365 \mathrm{~nm}$.

A classical plasma-driven source of metallic atoms in the gas phase is a low-pressure discharge rich in energetic ions. The ions accelerate in the potential sheath next to the negatively biased electrode and cause sputtering. The removed metal atoms (including some ions) pass into the gas phase, where they can agglomerate if the pressure is high enough. This technique was elaborated by Kylian et al. [42]. This technique allows the synthesis of nanoparticles with selected diameters and compositions, depending on the discharge parameters, as recently shown by the same group [43]. The nanoparticles are 
always spherical when using this technique. The production of nanoparticles by this method is limited by the sputtering rate, so it does not allow mass synthesis.

Figure 3 shows schematically that the reactions in the case zinc atoms are precursors. As mentioned above, the source of atoms can be thermal evaporation [7] or sputtering [42]. Zinc atoms are partially excited and ionized, while any metallic clusters, likely formed by strong discharges [7], assume a negative surface charge due to the attachment of slow plasma electrons. Oxidation and agglomeration occur in a similar manner as when $\mathrm{Zn}\left(\mathrm{CH}_{3}\right)_{2}$ is used as a precursor. In all cases, the synthesized $\mathrm{ZnO}$ nanoparticles tend to have spherical shapes, and the diameter depends on the synthesis conditions, including residence time in plasma, pressure, the concentrations of the various gases, the discharge power, and specifics of the plasma reactor.

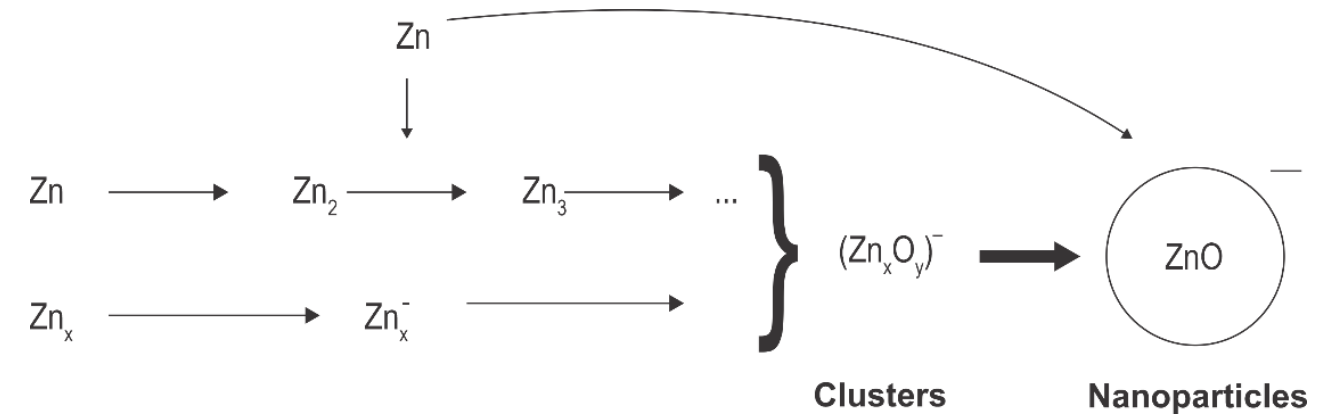

Figure 3. Schematic depiction of the reactions where zinc atoms or clusters are precursors.

The application of gaseous precursors (organometallic compounds or $\mathrm{Zn}$ vapour) may not be economical or may not ensure the desired quantities of nanoparticles. The next option is to feed zinc powder into a plasma reactor. Hiragino et al. [26] synthesized nitrogendoped $\mathrm{ZnO}$ nanoparticles using a medium-pressure gaseous plasma. The experimental system was almost identical to that presented in Figure 1a, except the microwave cavity was replaced with a coil connected to a radiofrequency $(\mathrm{RF})$ generator. The discharge was concentrated to a rather small volume inside a coil which was coupled to an RF generator operating at a power of up to $30 \mathrm{~kW}$ and a frequency of $3.5 \mathrm{MHz}$. The gas pressure was about 200 mbar. The authors managed to keep the wall temperature of the reactor at $300 \mathrm{~K}$ by using water cooling instead of the forced air, as shown in Figure 1a. Zinc powder with a diameter of about $140 \mu \mathrm{m}$ was used as the starting material. Based on the experimental details, the residence time of the powder in the hot plasma can be estimated to be about $0.1 \mathrm{~s}$. Upon passing through the hot, but still nonequilibrium plasma, nanoparticles of different morphologies and a size of about $100 \mathrm{~nm}$ were synthesized. The aspect ratio of any nanoparticle was close to 1 , and some agglomeration was observed, but the specific surface area of the synthesized $\mathrm{ZnO}$ materials was as large as about $20 \mathrm{~m}^{2} / \mathrm{g}$. The materials were found to be useful for light-emitting diode (LED) applications. The schematic of the synthesis of zinc oxide nanoparticles from powder precursors is shown in Figure 4.

The kinetics of $\mathrm{ZnO}$ nanoparticle formation using $\mathrm{Zn}$ powder as a precursor is different from that shown in Figure 2 or Figure 3. The interaction of oxygen-containing plasma with metallic substrates was elaborated long ago, and one of the first reports on the synthesis of large aspect ratio nanowires was published as [44]. The metallic powder heats up to a high temperature when exposed to rather powerful plasma. Therefore, the powder quickly melts and sometimes even evaporates if kept in a powerful plasma for too long. The oxidation of the melted powder can lead to a variety of morphological shapes [45], ranging from nanowires with very high aspect ratios to cauliflower-like structures. The formation of nanowires on the surface of metal powder is illustrated in Figure 4a. The detail of the growth mechanism is shown in Figure $4 \mathrm{~b}$. The surface of a thin oxide film is never perfectly smooth but rich in humps. The plasma electrons accumulate at the top of the humps due to the Faraday effect. This creates a static electric field along the hump. The $\mathrm{Zn}^{+}$ions enter the oxide layer and preferentially move in the direction of the electric field, i.e., along the 
hump, until they reach the tip of the hump, where they oxidize, thus lengthening the hump. A longer hump leads to further accumulation of the negatively charged electrons at the tip and thus even more extensive electro-diffusion of positive ions towards the tip. Finally, a nanowire with a large aspect ratio is formed. This mechanism, as shown in Figure $4 \mathrm{~b}$, works only under specific conditions, especially temperature. If the temperature is too low to enable diffusion of $\mathrm{Zn}^{+}$ions through the oxide layer and on through the hump, little oxidation takes place. When the temperature is too high, thermal diffusion predominates, electro-migration is not as efficient, and structures with poor aspect ratios are formed. In one work, the range of useful parameters for the growth of silica nanoneedles was found only between 1800 and $1850 \mathrm{~K}$ [38].

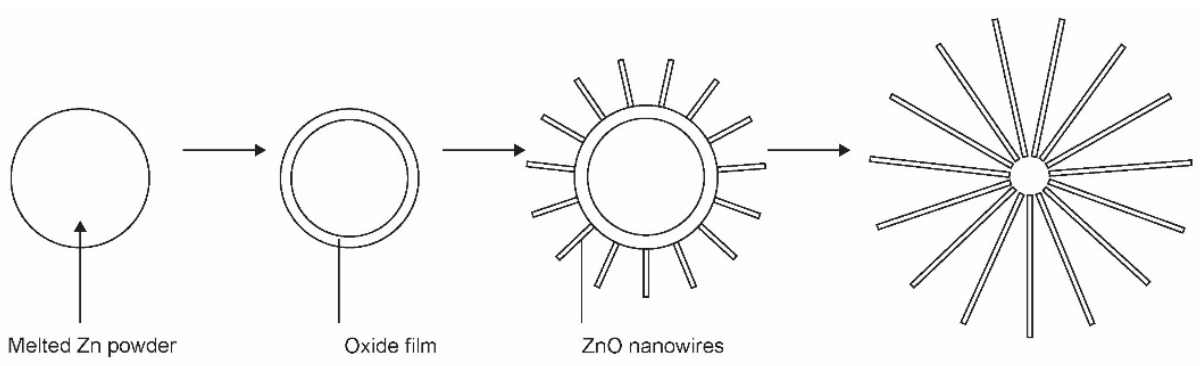

(a)

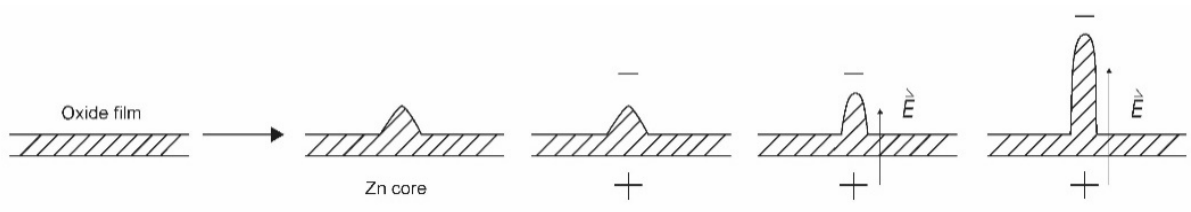

(b)

Figure 4. Schematic representation of the formation of nanoparticles with $\mathrm{Zn}$ powder as a precursor: (a) the formation of nanowires on the surface of metal powder; (b) the detail of the growth mechanism.

Yet, another alternative for deposition of zinc oxide nanoparticles using a low-pressure gaseous plasma was reported by Yang et al. [25]. They used the configuration as shown in Figure $1 \mathrm{~b}$ with some modifications to synthesize $\mathrm{ZnO}$ nanoparticles from $\mathrm{ZnCl}_{2}$ powder under low-pressure conditions. Instead of using microwave heating, a furnace was placed on a glass discharge tube to melt and heat the $\mathrm{ZnCl}_{2}$ powder to a temperature of about $350^{\circ} \mathrm{C}$, which allowed evaporation under controlled conditions. The vapour was directed toward a substrate by drifting a mixture of argon and oxygen in the direction from the precursor to the substrate. Weakly ionized gaseous plasma was generated in the discharge tube by an inductively coupled RF generator operating at a frequency of $13.56 \mathrm{MHz}$ and a power of $100 \mathrm{~W}$. The coil had the same function as the microwave cavity in Figure 1b. At plasma conditions, the vapour was partially atomized and the $\mathrm{Zn}$ atoms condensed on the substrate surface. The high concentration of oxygen atoms in the discharge tube allowed rapid oxidation of the deposited zinc. The treatment time was $15 \mathrm{~min}$. The $\mathrm{ZnO}$ nanoparticles formed dense pillars with a typical diameter of about $0.4 \mu \mathrm{m}$ and a length of several $\mu \mathrm{m}$. XRD characterization confirmed the hexagonal $\mathrm{ZnO}$ structure with the preferential growth of $\mathrm{ZnO}$ was along the c-axis, which was confirmed by the transmission electron microscope (TEM) observations. Neither a cubic $\mathrm{ZnO}$ phase nor $\mathrm{ZnCl}_{2}$ were found in the prepared product. Without plasma, only $\mathrm{ZnCl}_{2}$ was found on the substrate. This work clearly demonstrates the advantages of plasma conditions. The authors suggested several mechanisms occurring in the gas phase and at the surfaces and emphasized the importance of metastable $\mathrm{Ar}$ in $\mathrm{ZnCl}_{2}$ dissociation. The authors also reported that the addition of $\mathrm{O}_{2}$ to the gaseous plasma caused an enhancement of $\mathrm{ZnCl}_{2}$ dissociation. Optical emission spectroscopy was used to characterize the plasma; the radiative transitions of 
$\mathrm{Zn}$ atoms were significantly suppressed even with a small addition of oxygen to argon. The intensity of the $\mathrm{Zn}$ atomic lines decreased with increasing concentration of oxygen in the $\mathrm{Ar}-\mathrm{O}_{2}$ mixtures. The authors explained this by extensive oxidation of $\mathrm{Zn}$ in the gas phase. Therefore, the reaction mechanisms in the gas phase follow the initial case shown in Figure 3.

Sputtering or thermal evaporation using nonequilibrium low-pressure gaseous plasma may not be the most efficient atom sources due to limited power density and thus evaporation rate. Low-impedance discharges perform better as long as the evaporation intensity is the merit. Shanenkova et al. [7] reported the plasma synthesis of zinc oxide in an extremely short time process (duration less than $1 \mathrm{~ms}$ ) using an electric discharge zinc-containing plasma jet flowing into an oxygen atmosphere. They used a home-built, high-power, arclike plasma device operating in pulsed mode with the maximum discharge current of nearly $10^{5} \mathrm{~A}$. The total energy of each pulse was nearly $30 \mathrm{~kJ}$. The arc chamber was evacuated before igniting the discharge. The powered electrode was made of zinc, which vaporized upon the discharge conditions. Plasma was therefore sustained in metallic vapour. A shock wave formed during each discharge, and the plasma, rich in ionized metal vapour as well as very small $\mathrm{Zn}$ droplets, moved away from the main electrode at supersonic speed. The jet gradually cooled, allowing the clustering of $\mathrm{Zn}$ atoms in the gas phase, as shown schematically in Figure 4. The clusters oxidized in the oxygen-containing postdischarge chamber and grew by adsorption of $\mathrm{Zn}$ atoms. Complete oxidation of nanoparticles was observed. Various morphological shapes other than nanowires were found by TEM. Details about this unique device used for the synthesis of nanoparticles with typical dimensions of around $100 \mathrm{~nm}$ were reported in another work of the same group [29].

\subsection{Hot Atmospheric-Pressure Plasmas}

The thermalization of plasma radicals and charged particles in the gas phase is a quick process at atmospheric pressure. Charged particles are created in the volume of a high electric field where the electrons gain enough energy for multiplication at ionization collisions with gaseous molecules or atoms. Outside this volume, the neutralization of charged particles, the association of radicals with stable molecules and relaxation of excited particles is so efficient that the density of reactive species is marginal. A couple of distinguished discharges are used for sustaining plasma at atmospheric pressure: the low-impedance electric arcs (often called plasma torches) and high-impedance discharges such as corona and dielectric-barrier discharges. A schematic of two devices useful for synthesizing $\mathrm{ZnO}$ nanoparticles using a low-impedance discharge is shown in Figure 5. Figure 5a shows a typical arc plasma powered by a low-impedance direct current (DC) discharge. The precursor, either organometallic or metal powder, is fed in the gas before the discharge zone or into the plasma plume. In the case of Figure $5 b$, the plasma plume is sustained with an electrodeless discharge, typically powered with an RF generator of frequency between 10 and $1000 \mathrm{kHz}$. In both cases, the gas temperature inside the plasma plume is around $10,000 \mathrm{~K}$.

Lee et al. [37] developed a technique to synthesize high-quality $\mathrm{ZnO}$ nanoparticles by passing a relatively spherical zinc powder through an atmospheric pressure plasma. The plasma was sustained in air or a mixture of nitrogen and oxygen by a microwave discharge at a frequency of $2.45 \mathrm{GHz}$ in a reaction chamber similar to the configuration of Figure $5 \mathrm{~b}$ except that the microwave (MW) cavity was too small (and the electromagnetic field so dense) to enable sustaining plasma even at atmospheric pressure. The density of charged particles in the core plasma was about $10^{19} \mathrm{~m}^{-3}$. The kinetic temperature of the neutral gas reached $6500 \mathrm{~K}$, similar to the arc discharges of Figure 5. The zinc powder melted under these harsh conditions and solidified after leaving the volume of the intense plasma. The powder was also oxidized during the plasma treatment, and the resulting $\mathrm{ZnO}$ particles took on interesting morphologies that depended on the details of the processing parameters. When compressed air was used, $\mathrm{ZnO}$ nanowires and tetrapods were synthesized. The concentration of nanowires was much larger than other morphological 
forms. Dense nanowires with diameters of about $100 \mathrm{~nm}$ and lengths of a few $\mu \mathrm{m}$ grew from particles with smaller aspect ratios under plasma conditions. The synthesis mechanism was similar to that illustrated in Figure 3. Both nanowires and tetrapods were singlecrystalline. When the compressed air was replaced by high purity synthetic air or pure oxygen, a large number of nanoparticles grew from zinc powder, but they had more complex crystalline structures. The differences were explained by the presence of water vapour and some gaseous impurities in the compressed air, which were not present in pure gases. Optical absorption in the UV range (probed between 200 and $400 \mathrm{~nm}$ ) was large for all morphological forms, but absorption in the visible range was found to be much larger for nanowires than for tetrapods. The photoluminescence of all $\mathrm{ZnO}$ materials peaked in the range between 350 and $360 \mathrm{~nm}$.

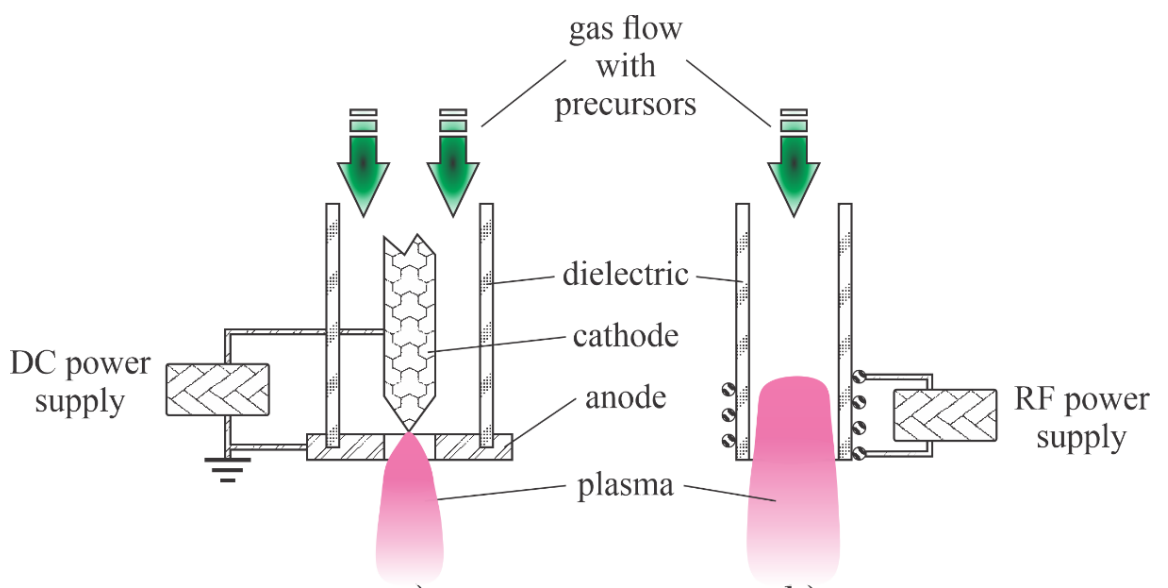

a)

b)

Figure 5. Direct current (DC) plasma arc (a) and radio frequency (RF) plasma torch (b).

A standard configuration of the atmospheric-pressure electric arc is shown in Figure 5a. Such a configuration of the discharge power $70 \mathrm{~kW}$ was used by Ko et al. [35] to synthesize ultrafine $\mathrm{ZnO}$ nanopowders. They used either pure nitrogen or a mixture of nitrogen and argon as carrier gases and commercial zinc powders as precursors. The powder melted and almost fully evaporated in the powerful discharge and the metallic vapour condensed when leaving the hot plasma. Oxidizing impurity gases assured for simultaneous oxidation of the nanoparticles upon solidification. Most synthesized nanoparticles were spherical of a typical diameter of several $10 \mathrm{~nm}$, but more complex geometries were also found. The aspect ratio of such morphological features was not large, though. The production rate was over $1 \mathrm{~kg} / \mathrm{h}$. The configuration in Figure $5 \mathrm{a}$ therefore enables the rapid synthesis of rather large quantities of almost spherical $\mathrm{ZnO}$ nanoparticles.

A similar device was also used by Murali and Sohn [36] except that they used zinc nitrate powder of typical dimension $50 \mu \mathrm{m}$ as the precursor. The discharge power was $15 \mathrm{~kW}$ and the Ar the carrier gas. As in the case of Ko et al. [35], the rather large powder melted and evaporated while passing the discharge zone, and the vapours condensed in the postglow region to form almost perfectly spherical nanoparticles on various diameters between about 10 and $50 \mathrm{~nm}$. The formation of the nanoparticles followed the scheme presented in Figure 3. A more thorough explanation of the method is presented in the recent paper [46] of the same authors. An earlier review on the plasma arc synthesis of various nanoparticles using the configuration in Figure 5 a was published by Seo and Hong [47].

A DC plasma source as shown in Figure 5a was also applied by Yu et al. [34]. Unlike the previously cited authors, Yu prepared an aqueous solution of zinc acetate and nitrate and sprayed the liquid into the plasma plume. The discharge was sustained in a mixture of argon and hydrogen. As a result of the spraying, the water quickly evaporated and dissociated upon plasma conditions, so the plasma was also rich in $\mathrm{OH}$ radicals as 
well as $\mathrm{O}$ atoms and ions. A substrate was placed in the agglomeration zone (a few $\mathrm{cm}$ from the plasma plume), so the nanoparticles were still hot upon impinging the substrate. Such a configuration was found useful for the synthesis of $\mathrm{ZnO}$ thin films with dense nanoparticles in different morphological shapes. The authors provided a schematic of the solution precursor plasma spray technology and the potential clusters from the different zinc solution precursors. Using pure $\mathrm{Zn}$-acetate, the nanostructured morphologies were clearly observed. The films exhibited hierarchical microstructures composed of sea-urchinand aloe-vera-like structures. The $\mathrm{ZnO}$ samples prepared from pure $\mathrm{Zn}$-nitrate solutions exhibited classic porous microstructures composed of agglomerates of irregular particles or flatten splats. The clustering at the edge of the plasma plume where the temperature was reasonably low followed the reaction presented schematically in Figure 2, but the rich morphology observed in some samples indicates that the growth of the oxide nanostructures only occurred at a cooler zone of the discharge or even on the surface of the samplenamely, the morphology also exhibited nanospikes of very large aspect ratios, which is typical for the growth of the oxide film at conditions where the electro-migration prevails (Figure 3). In any case [34], clearly demonstrates that the morphology of $\mathrm{ZnO}$ surface films depends largely on small details in the composition of the sprayed precursors, which in turn influence the behaviour of plasma-in particular, the concentration of reactive plasma species in the early afterglow zone of the arc discharge.

The proximity of substrate to the edge of the hot plasma plume in the configuration shown in Figure 5b was also demonstrated by Wallenhorst et al. [48]. In fact, they developed a technique for deposition of nanostructured films on different substrates in the continuous mode. The substrate passed through the plasma jet at a speed of $4-5 \mathrm{~cm} / \mathrm{s}$. The working distance between the edge of the plasma plume and the substrate was about $2 \mathrm{~cm}$. The discharge was ignited at the DC voltage of $15 \mathrm{kV}$ and sustained at the effective voltage amounts of 2-3 kV. The input power reached a maximum of $2 \mathrm{~kW}$, where high voltage pulses with a pulse duration of $5-10 \mu$ s and a pulse repetition rate of $50 \mathrm{kHz}$ are applied. $\mathrm{Zn}$ powder of particle size about $13 \mu \mathrm{m}$ was injected continuously into the plasma plume. A semicontinuous film rich in dense crystallites of $\mathrm{ZnO}$ was observed on the sample surfaces. Despite the rather large size of precursor particles, an almost closed basic layer of very small, nanometre-sized particles in between larger particles and/or agglomerates was detected. The existence of particles at the nanoscale was explained by the melting and vaporization of initial particles within the hot plasma zone and selective deposition of an almost closed layer of small particles and some agglomerated big clusters. Due to the relatively low power, the pulsed character of the discharge and the short residence time in the plasma plume caused the rich morphology, as observed by Yu et al. [34].

The configuration illustrated in Figure $5 b$ was used by Yoo et al. [24]. They used argon as the carrier gas and zinc oxide powder with an average diameter of $1 \mu \mathrm{m}$. Despite the high discharge power up to $60 \mathrm{~kW}$ and the small size of the precursor powder, some unmelted powders were found in the collection chamber. Most powders, however, melted and evaporated in the hot plasma. The vapours and perhaps droplets of melted $\mathrm{ZnO}$ condensed in the postglow and formed spherical nanoparticles of diameters of several $10 \mathrm{~nm}$. Some experiments were also performed at a somehow lower pressure (about $0.5 \mathrm{bar}$ ) and other morphological shapes were observed. No features of a high aspect ratio were detected by dropping the precursors through the discharge of Figure $5 b$ though. The results reported by Yoo et al. [24], therefore, confirm the hypothesis that the nonequilibrium conditions are needed for plasma synthesis of metal oxide nanoparticles of high aspect ratios. As mentioned above, the mechanism illustrated in Figure 3 performs well only when a significant deviation from thermal equilibrium occurs. Otherwise, the spherical shape predominates since the spheres are the most thermodynamically stable forms of small particles. In another set of experiments, the authors managed to prolong the residence time of precursors in the early postdischarge region [24]. When using the extreme conditions (residence time of several seconds), much richer morphological shapes were observed. In fact, nanoflowers consisting of many hexagonal nanorods having lengths of a few $\mu \mathrm{m}$ and 
diameters of several $100 \mathrm{~nm}$. Since the initial nanodroplets passed the extended growth region with enough residence time and abundant resources, the foundational nucleation seeds were formed and combined with floating $\mathrm{ZnO}$ molecules to assemble nanocrystal systems following the scheme presented in Figure 3.

\subsection{Cold Atmospheric-Pressure Plasmas}

$\mathrm{ZnO}$ nanoparticles are often required as desired surface finish of other materials. In such cases, the adhesion of the nanoparticles synthesized by any technique described above may be insufficient. If adhesion is a problem, one solution may be to deposit the precursor on the substrate, followed by plasma treatment. The gaseous plasma should be cold enough to prevent melting or other thermal damage of the substrate. Even a brief exposure of a zinc plate to nonequilibrium plasma can cause a significant modification of the surface morphology. Zhang et al. [30] reported a simple method to fabricate $\mathrm{ZnO}$ nanosheet-assembly film by cold plasma sustained in ambient air. They used a double dielectric barrier discharge (DBD) to sustain the gaseous plasma. The device is illustrated in Figure 6a. An alumina ceramic plate backed by an electrode served as a holder for a zinc plate. Another plate was made of glass and provided with a counter-electrode. The electrodes were connected to a $5 \mathrm{~Hz}$ sine-wave power generator operating at a voltage of $12 \mathrm{kV}$. A filamentary discharge occurred in the volume between the electrodes, and gaseous plasma interacted with the zinc plate. A variety of zinc nitrates were found on the surface of the zinc plate by XRD analysis. Some samples were then heated to about $250{ }^{\circ} \mathrm{C}$ to allow the formation of $\mathrm{ZnO}$ in the form of nanowalls with a thickness of a few $10 \mathrm{~nm}$ and a distance between adjacent nanowalls of a few $100 \mathrm{~nm}$. The unique morphological features were explained by localized heating of the zinc plate. The very low-frequency discharge caused streamers of fast electrons to hit the zinc surface. The electron streamers caused localized ionization and dissociation of gaseous molecules. The energy dissipated locally on the zinc plate surface was high enough to cause both oxidation and heating, which led to a locally high temperature and thus high mobility of atoms at the surface and below the surface. The presence of water vapour and reactive nitrogen species caused the formation of complex compounds.

a)

b)

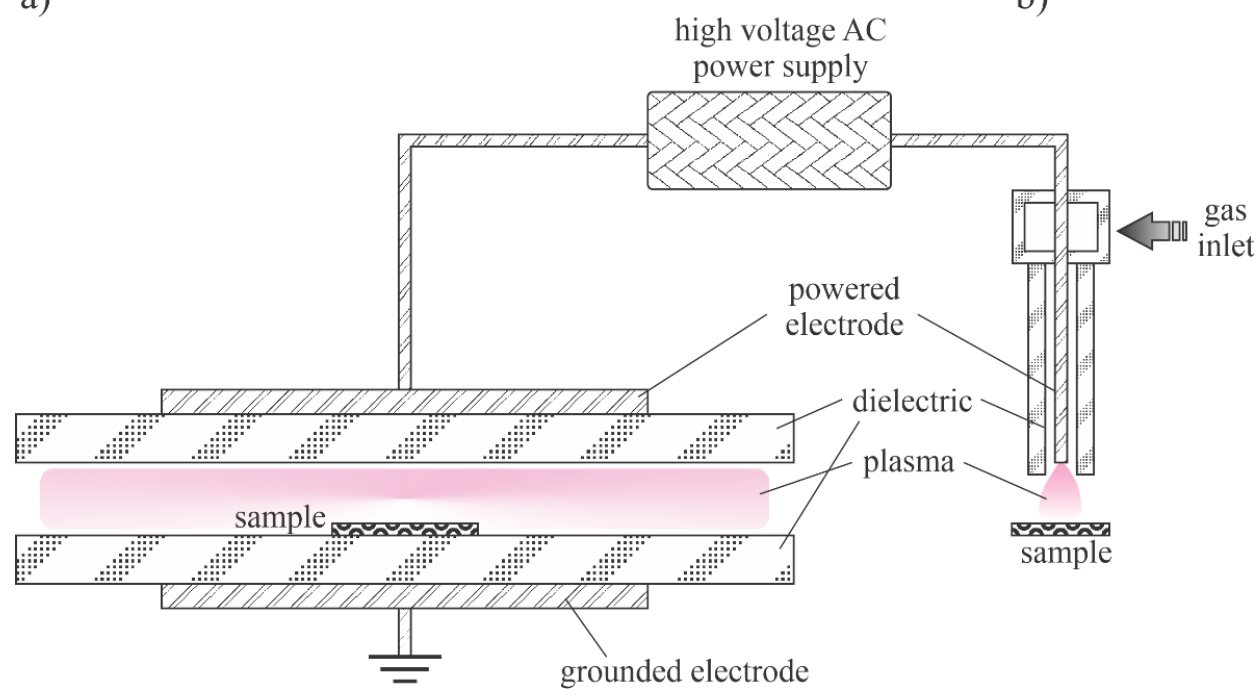

Figure 6. Schematic of a device useful for sustaining nonequilibrium plasma at atmospheric pressure. (a) —Plane parallel and (b) - jet configurations.

A thin film of zinc-containing material can also be converted to $\mathrm{ZnO}$ nanoparticles upon treatment with filamentary DBD in the configuration illustrated in Figure 6b. A nitrogen DC-pulsed atmospheric pressure plasma jet (APPJ) was used by Lee at al. [33] to synthesize platinum-decorated $\mathrm{ZnO}$ nanoparticles. Chloroplatinic acid dissolved in 
isopropanol and zinc acetate in deionized water were mixed, stirred well and spin-coated onto fluorine doped tin oxide (FTO) substrates. The thin film was then treated with APPJ. The plasma treatment allowed the conversion of the coated film into high-quality $\mathrm{ZnO}$ nanoparticles decorated with metallic platinum. The effects were explained by rapid chemical reactions induced by the plasma treatment, as well as by thermal effects. The same coatings were also cured in an oven, and the plasma-treated materials exhibited higher quality, which was explained by the interaction of plasma radicals of high excitation energy with the deposited film. The materials were found to be useful as counter electrodes of dye-sensitized solar cells.

The low-frequency alternative current (AC) or pulsed DC discharges at atmospheric pressure are not able to sustain a homogeneous plasma as the lifetime of the reactive species at 1 bar is nearly $1 \mu \mathrm{s}-$ much shorter than the duration of a low-frequency AC discharge, let alone a DC-pulsed discharge. Such discharges result in the formation of one or a few current pulses due to the formation of electron streamers. A bunch of such streamers is often called a filament. The density of charged particles in a streamer is usually greater than in a continuous low-pressure plasma (Figure 1). Therefore, for a short time, extensive surface chemistry takes place at a small spot on the material when it interacts with the streamer. These spots are locally heated to a high temperature, which is often sufficient to convert a continuous film of the deposited precursor to $\mathrm{ZnO}$ nanoparticles, despite the rather low average temperature of the substrate. Figure 7 illustrates the effect of a streamer on the substrate surface. Numerous streamers affect larger surface areas, but the nanoparticles may vary in morphology or even composition from spot to spot, depending on the intensity of each streamer. The nanoparticles can adhere well to the substrate as not all of the precursor needs to be oxidized.

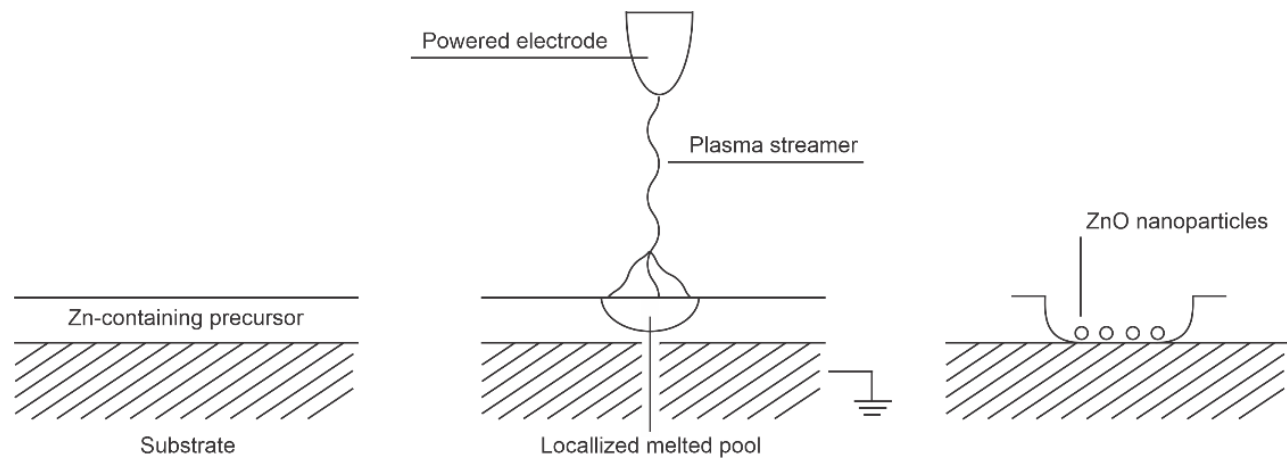

Figure 7. Interaction between low-frequency atmospheric pressure discharges and Zn-containing surface film.

An advanced method for low-temperature oxidation of $\mathrm{Zn}$-containing organic precursors is based on atomic layer deposition (ALD). This method is promising in microelectronics as only the surface atoms should chemically interact with the gas environment, so, at least theoretically, the oxidation could be carried out at room temperature. Mai et al. [27] reported the deposition of uniform, smooth, stoichiometric, and highly transparent $\mathrm{ZnO}$ films from organometallic precursors. They focused on bis-3-(N,N-dimethylamino)propyl zinc (II) ([Zn(DMP $\left.\left.)_{2}\right]\right)$. The authors used the plasma-assisted atomic layer deposition method under low-pressure conditions. The organometallic precursors were heated to an elevated temperature and condensed on silicon wafers in the form of a very thin film (about one monolayer). The deposition time was about $0.1 \mathrm{~s}$. Oxygen was then injected into the experimental system, and the plasma was ignited, allowing reactive oxygen species to completely calcinate the extremely thin organometallic film. The plasma was powered with a capacitively coupled RF discharge at $13.56 \mathrm{MHz}$ and nominal discharge power of $200 \mathrm{~W}$. The oxygen was introduced into the chamber by pulses of $500 \mathrm{~ms}$, in which the plasma was ignited for $150 \mathrm{~ms}$. Such a treatment time was long enough for the calcination of the monolayer of the organometallic precursor. The process was repeated several times until a 
$\mathrm{ZnO}$ layer of thickness several $10 \mathrm{~nm}$ was formed on the substrate. Incomplete calcination was observed at shorter plasma treatment times, indicating the importance of plasma species on the calcination process. Films of good quality were observed even at substrate temperature as low as $60^{\circ} \mathrm{C}$. Therefore, this technique is suitable for the deposition of $\mathrm{ZnO}$ films on heat-sensitive objects due to the favourable calcination temperature. The chemical reactions between reactive oxygen species and the deposited thin layer of organometallics are apparently extensive enough to allow complete oxidation over a time scale of well below $1 \mathrm{~s}$. However, the need for numerous repetitions of deposition and calcination phases may be a drawback. The procedure is shown schematically in Figure 8.

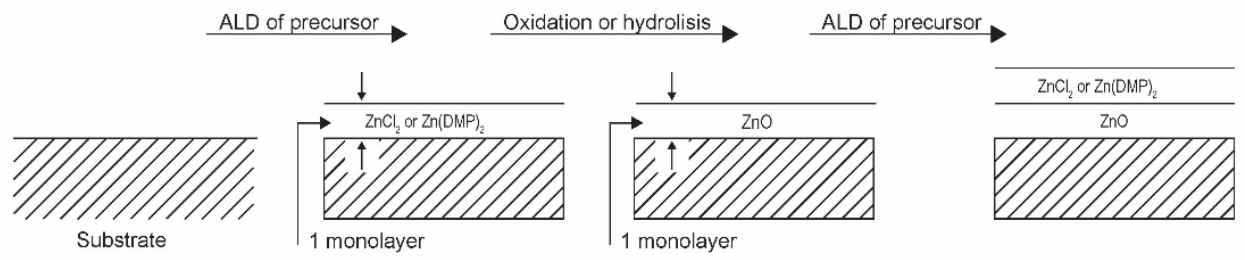

Figure 8. Oxidation of extremely thin layers of Zn-containing precursors.

Other precursors have been used in the atomic layer deposition of $\mathrm{ZnO}$ films. For example, Kopalko et al. [6] used zinc acetate $\left(\mathrm{Zn}\left(\mathrm{CH}_{3} \mathrm{COO}\right)_{2}\right)$ as a precursor but reported several obstacles that prevented the deposition of a uniform film in a reasonable time. The authors avoided oxidation of the precursor film by oxygen plasma and preferred hydrolysis. As a result, the required temperature to perform calcination was found to be around $300{ }^{\circ} \mathrm{C}$. They also investigated zinc chloride as a precursor film, but the desired temperature to achieve the hydrolysis in a reasonable time was $500{ }^{\circ} \mathrm{C}$. In any case, the resulting morphology of $\mathrm{ZnO}$ materials obtained by oxidation or hydrolysis of very thin films of $\mathrm{Zn}$-containing precursors leads to the formation of at least semicontinuous films instead of high-quality $\mathrm{ZnO}$ nanoparticles.

\subsection{Plasma Treatment of Liquid Precursor}

Zinc oxide nanoparticles can also be synthesized by plasma treatment of liquid precursors. Shutov et al. [3] developed a technique for the synthesis of powdered zinc oxide using plasma sustained over an aqueous zinc nitrate solution prepared by dissolving analytical grade $\mathrm{Zn}\left(\mathrm{NO}_{3}\right)_{2} \cdot \mathrm{x} \cdot 6 \mathrm{H}_{2} \mathrm{O}$ in distilled water. The distance between the electrodes and the liquid solution was several $\mathrm{cm}$, and the treatment time was $10 \mathrm{~min}$. As a result of such indirect plasma treatment, a colloidal solution was formed in the anode compartment of the electrolytic cell. A precipitate was formed at the bottom of the cell. XRD characterization of the synthesized particles revealed a mixture of hydroxide nitrate hydrate, zinc hydroxide nitrate, zinc hydroxide and zinc oxide. The concentration of $\mathrm{ZnO}$ was a few percent, and the particles of a typical size of a few $\mu \mathrm{m}$ had a low aspect ratio. Plasma-assisted synthesis of zinc oxide nanomaterials was also reported by Ananth et al. [31]. A plasma jet was generated with a DBD discharge operated in the air at ambient pressure. The discharge was powered with a pulsed AC generator at a voltage of about $500 \mathrm{~V}$ and a current of $100 \mathrm{~mA}$. An aqueous solution of zinc nitrate hexahydrate was used as a precursor. The plasma plume was about $1 \mathrm{~cm}$ away from the liquid surface so that the solution was treated by radicals in the flowing afterglow and any radiation arising from the glowing plasma that was not absorbed in the air. The plasma radicals were allowed to interact with the liquid for one hour. The temperature of the liquid remained below $30^{\circ} \mathrm{C}$ throughout the treatment. A significant portion of the water had evaporated before the treatment was complete, revealing interesting interaction mechanisms. The plasma radicals allowed the formation of nanoparticles with various morphologies, including nonuniform $\mathrm{ZnO}$ cubes with a typical size of about $300 \mathrm{~nm}$, nanorods with a length of up to about $1 \mu \mathrm{m}$ and an aspect ratio of about 10, nanopillars with a length of just over $1 \mu \mathrm{m}$ and an aspect ratio of about 3 , flower-like structures with a typical size over $1 \mu \mathrm{m}$, and various agglomerates. 
Other morphological forms were observed when the precursor was replaced by sulphate heptahydrate or zinc chloride. In the case of sulphate, layered structures were observed. The authors suggested a number of processes that could be involved in the synthesis of the nanoparticles by precipitation during the plasma treatment, such as the dissolution of the plasma ions in the solvent and the recombination leading to the release of corresponding gases, which requires sufficient activation energy, or a sufficiently strong electric field. The $\mathrm{XRD}$ analyses revealed predominantly hexagonal wurtzite $\mathrm{ZnO}$ with some defects. The antibacterial activity of the $\mathrm{ZnO}$ nanomaterials showed strong shape-dependent properties and exhibited a high inhibition effect against several types of bacteria. The synthesis of $\mathrm{ZnO}$ (and other) nanoparticles from liquids is shown in Figure 9.

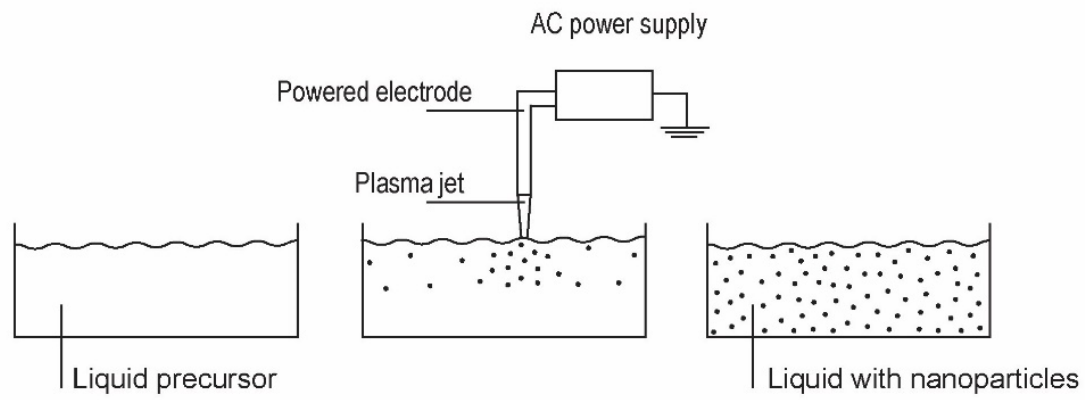

Figure 9. A typical setup for the synthesis of $\mathrm{ZnO}$ nanoparticles in liquids.

Plasma-induced synthesis of $\mathrm{ZnO}$ nanoparticles from liquid precursors was also reported by Tsumaki et al. [32]. They used atmospheric pressure plasma powered by a DBD discharge, similar to that shown in Figure $6 \mathrm{~b}$. The AC voltage source operated at a voltage of about $15 \mathrm{kV}$ and a frequency of $29 \mathrm{kHz}$. Helium served as the process gas, and small droplets of zinc-containing precursors were fed into the discharge zone. The droplets contained an aqueous solution of zinc acetate dehydrates. The droplets dimensions depended on the atomizer setting, but a typical diameter was about $1 \mu \mathrm{m}$. As a result of the plasma treatment, a large number of $\mathrm{ZnO}$ nanoparticles were formed as they passed through the plasma zone. Both spherical particles and flakes formed upon plasma treatment, and a typical dimension was in the submicrometre range. The XRD showed a wurtzite structure. The diameter of spherical particles slightly depended on the concentration of precursor in the aqueous solution. In general, the particle diameter increased with increasing concentration, but the effect was not dramatic. The plasma was characterized by optical spectroscopy. The high-resolution spectrum of $\mathrm{OH}$ emissions with a band head at about $309 \mathrm{~nm}$ was recorded to estimate the rotational temperature of $\mathrm{OH}$ radicals, which was expected to be nearly equal to the gas kinetic temperature. The scientifically pristine theoretical spectrum was simulated and compared to determine the gas temperature in the glowing plasma, which was found close to $1000 \mathrm{~K}$. A significant amount of water therefore evaporated, so the processes involved upon passing the droplets through plasma may be a combination of reactions, as illustrated in Figures 2 and 9.

\section{Conclusions}

The literature review shows various methods for the synthesis of $\mathrm{ZnO}$ nanoparticles using nonequilibrium gaseous plasma. The precursors can be added directly into the gaseous plasma. In such cases, the plasma reactors operate at low-pressure conditions to avoid agglomeration of the synthetized $\mathrm{ZnO}$ nanoparticles. An interesting alternative is to apply an atmospheric-pressure plasma jet and feed precursors dissolved in small water droplets. In such cases, the water evaporates at least partially under the plasma conditions and the precursor transforms into $\mathrm{ZnO}$ nanoparticles. The water solutions in an appropriate container can be exposed to the atmospheric-pressure gaseous plasma, and the nanoparticles form without the need for water evaporation. However, controlling the morphological properties of $\mathrm{ZnO}$ nanoparticles synthesized in liquids remains a scientific 
challenge. Ex situ synthesized nanoparticles may not adhere well to a substrate. To overcome the problem of insufficient adhesion of $\mathrm{ZnO}$ nanoparticles to substrates, a precursor was deposited on a substrate and then treated with gaseous plasma. This technique often enables good adhesion of the $\mathrm{ZnO}$ film formed from the precursor, but the zinc oxide may be in the form of a semicontinuous film rather than adequately distributed nanoparticles. An alternative is the application of hot plasmas sustained by low-impedance discharges at atmospheric pressure. Precursors melt in the plasma plume. If the substrate is placed a few $\mathrm{cm}$ from the region of hot plasma in the direction of the gas jet, the nanoparticles remain hot enough to stick well on the substrate and form a film that may have a rich morphology. Decoration of heat-sensitive substrates with well-adhered uniformly distributed $\mathrm{ZnO}$ nanoparticles of suitable size and morphology, however, remains a scientific challenge.

Author Contributions: Writing, review, and editing, G.P.; literature search, schematics, and editing, K.B.; literature overview, writing, review, and editing, M.M.; conceptualization, supervision, review, and editing, M.G. All authors have read and agreed to the published version of the manuscript.

Funding: The authors acknowledge the financial support from the Slovenian Research Agency: research core funding No. P2-0082 "Thin-film structures and plasma surface engineering" and project "Ecologically friendly in situ synthesis of $\mathrm{ZnO}$ nanoparticles for the development of protective textiles", ID J2-1720.

Conflicts of Interest: The authors declare no conflict of interest.

\section{References}

1. Faure, B.; Salazar-Alvarez, G.; Ahniyaz, A.; Villaluenga, I.; Berriozabal, G.; De Miguel, Y.R.; Bergström, L. Dispersion and surface functionalization of oxide nanoparticles for transparent photocatalytic and UV-protecting coatings and sunscreens. Sci. Technol. Adv. Mater. 2013, 14, 23001-23024. [CrossRef] [PubMed]

2. Smijs, T.G.; Pavel, S. Titanium dioxide and zinc oxide nanoparticles in sunscreens: Focus on their safety and effectiveness. Nanotechnol. Sci. Appl. 2011, 4, 95-112. [CrossRef] [PubMed]

3. Shutov, D.A.; Rybkin, V.V.; Ivanov, A.N.; Smirnova, K.V. Synthesis of zinc oxide powders in plasma-solution systems. High Energy Chem. 2017, 51, 65-69. [CrossRef]

4. Shahin, S.M.T.; Montazer, M. Diverse-shaped ZnO nanoparticles on polyester fabric through assorted in situ methods: Studying plasma treatment order and different alkali media. J. Text. Inst. 2020. [CrossRef]

5. Verbič, A.; Gorjanc, M.; Simončič, B. Zinc Oxide for Functional Textile Coatings: Recent Advances. Coatings 2019, 9, 550. [CrossRef]

6. Kopalko, K.; Wójcik, A.; Godlewski, M.; Łusakowska, E.; Paszkowicz, W.; Domagała, J.Z.; Godlewski, M.M.; Szezerbakow, A.; Świątek, K.; Dybko, K. Growth by atomic layer epitaxy and characterization of thin films of ZnO. Phys. Status Solidi (C) 2005, 2, 1125-1130. [CrossRef]

7. Shanenkova, Y.; Sivkov, A.; Ivashutenko, A.; Shanenkov, I.; Firsov, K. Plasma dynamic synthesis of ultradispersed zinc oxide and sintering ceramics on its basis by SPS method. IOP Publ. IOP Conf. Ser. J. Phys. Conf. Ser. 2016, 755, 12117. [CrossRef]

8. Gorjanc, M.; Jazbec, K.; Šala, M.; Zaplotnik, R.; Vesel, A.; Mozetič, M. Creating cellulose fibres with excellent UV protective properties using moist CF4 plasma and ZnO nanoparticles. Cellulose 2014, 21, 3007-3021. [CrossRef]

9. Primc, G.; Tomšič, B.; Vesel, A.; Mozetič, M.; Ražić, S.E.; Gorjanc, M. Biodegradability of oxygen-plasma treated cellulose textile functionalized with $\mathrm{ZnO}$ nanoparticles as antibacterial treatment. J. Phys. D Appl. Phys. 2016, 49, 324002. [CrossRef]

10. Debanath, M.K.; Karmakar, S. Study of blueshift of optical band gap in zinc oxide (ZnO) nanoparticles prepared by lowtemperature wet chemical method. Mater. Lett. 2013, 111, 116-119. [CrossRef]

11. Divya, B.; Karthikeyan, C.; Rajasimman, M. Chemical Synthesis of Zinc Oxide Nanoparticles and Its Application of Dye Decolourization. Int. J. Nanosci. Nanotechnol. 2018, 14, 267-275.

12. Shaba, E.Y.; Jacob, J.O.; Tijani, J.O.; Suleiman, M.A.T. A critical review of synthesis parameters affecting the properties of zinc oxide nanoparticle and its application in wastewater treatment. Appl. Water Sci. 2021, 11, 48. [CrossRef]

13. Hsieh, C.-H. Spherical Zinc Oxide Nano Particles from Zinc Acetate in the Precipitation Method. J. Chin. Chem. Soc. 2007, 54, 31-34. [CrossRef]

14. Ramgir, N.S.; Late, D.J.; Bhise, A.B.; More, M.A.; Mulla, I.S.; Joag, D.S.; Vijayamohanan, K. ZnO multipods, submicron wires, and spherical structures and their unique field emission behavior. J. Phys. Chem. B 2006, 110, 18236-18242. [CrossRef] [PubMed]

15. Samanta, P.K.; Saha, A.; Kamilya, T. Morphological and optical property of spherical ZnO nanoparticles. Optik 2015, 126, 1740-1743. [CrossRef]

16. Wang, X.; Ahmad, M.; Sun, H. Three-dimensional ZnO hierarchical nanostructures: Solution phase synthesis and applications. Materials 2017, 10, 1304. [CrossRef]

17. Li, D.; Li, Y.; Zhang, Y.; Chang, F. Facile synthesis of three-dimensional ZnO hierarchical microspheres composed of well-ordered nanorods by hydrothermal method. Results Phys. 2019, 12, 953-958. [CrossRef] 
18. Koodziejczak-Radzimska, A.; Markiewicz, E.; Jesionowski, T. Structural characterisation of ZnO particles obtained by the emulsion precipitation method. J. Nanomater. 2012, 2012, 1-9. [CrossRef]

19. Yi, G.C.; Wang, C.; Park, W.I. ZnO nanorods: Synthesis, characterization and applications. Semicond. Sci. Technol. 2005, 20 , S22. [CrossRef]

20. Zhang, Y.; Ram, M.K.; Stefanakos, E.K.; Goswami, D.Y. Synthesis, characterization, and applications of ZnO nanowires. J. Nanomater. 2012, 2012, 1-23. [CrossRef]

21. Choudhary, S.; Sahu, K.; Bisht, A.; Satpati, B.; Mohapatra, S. Rapid synthesis of ZnO nanowires and nanoplates with highly enhanced photocatalytic performance. Appl. Surf. Sci. 2021, 541, 148484. [CrossRef]

22. Valente, P.; Seré, A.; Pereyra, C.J.; Campo, L.; Spera, E.; Castillo, J.; Helvia, S.A.; del Río, R.; Ramírez, D.; Riveros, G.; et al. Comparative analysis between nanorods and nanowires by using depolarized and diffuse light. Opt. Commun. 2021, $478,126393$. [CrossRef]

23. Kleinwechter, H.; Janzen, C.; Knipping, J.; Wiggers, H.; Roth, P. Formation and properties of ZnO nano-particles from gas phase synthesis processes. J. Mater. Sci. 2002, 37, 4349-4360. [CrossRef]

24. Yoo, H.I.; Mauchauffé, R.; Moon, S.Y. Fabrication of zinc oxide nano-structures in RF inductively-coupled thermal plasma and their photoluminescence effects. Curr. Appl. Phys. 2021, 25, 18-23. [CrossRef]

25. Yang, R.; Zheng, J.; Li, W.; Qu, J.; Zhang, X.; Li, X. Low-temperature growth of ZnO nanostructures by oxygen plasma oxidation of ZnCl2. Mater. Chem. Phys. 2011, 129, 693-695. [CrossRef]

26. Hiragino, Y.; Tanaka, T.; Takeuchi, H.; Takeuchi, A.; Lin, J.; Yoshida, T.; Fujita, Y. Synthesis of nitrogen-doped ZnO nanoparticles by RF thermal plasma. Solid State Electron. 2016, 118, 41-45. [CrossRef]

27. Mai, L.; Mitschker, F.; Bock, C.; Niesen, A.; Ciftyurek, E.; Rogalla, D.; Mickler, J.; Erig, M.; Li, Z.; Awakowicz, P.; et al. From Precursor Chemistry to Gas Sensors: Plasma-Enhanced Atomic Layer Deposition Process Engineering for Zinc Oxide Layers from a Nonpyrophoric Zinc Precursor for Gas Barrier and Sensor Applications. Small 2020, 16, 1907506. [CrossRef] [PubMed]

28. Subannajui, K. Super-fast synthesis of ZnO nanowires by microwave air-plasma. Chem. Commun. 2016, 52, 3195-3198. [CrossRef] [PubMed]

29. Sivkov, A.; Ivashutenko, A.; Shanenkova, Y.; Shanenkov, I. Plasma dynamic synthesis and obtaining ultradispersed zinc oxide with single-crystalline particle structure. Adv. Powder Technol. 2016, 27, 1506-1513. [CrossRef]

30. Zhang, W.; Li, C.; Tian, Z.; Wang, Y.; Hou, Z. Preparation of ZnO nanosheet-assembly film on zinc plate by cold plasma. Thin Solid Film. 2020, 712, 138274. [CrossRef]

31. Ananth, A.; Dharaneedharan, S.; Seo, H.J.; Heo, M.S.; Boo, J.H. Soft jet plasma-assisted synthesis of Zinc oxide nanomaterials: Morphology controls and antibacterial activity of ZnO. Chem. Eng. J. 2017, 322, 742-751. [CrossRef]

32. Tsumaki, M.; Shimizu, Y.; Ito, T. Size-controlled sub-micrometer spheroidized ZnO particles synthesis via plasma-induced processing in microdroplets. Mater. Lett. 2016, 166, 81-84. [CrossRef]

33. Lee, C.C.; Wan, T.H.; Hsu, C.C.; Cheng, I.C.; Chen, J.Z. Atmospheric-pressure plasma jet processed Pt/ZnO composites and its application as counter-electrodes for dye-sensitized solar cells. Appl. Surf. Sci. 2018, 436, 690-696. [CrossRef]

34. Yu, Z.; Moussa, H.; Liu, M.; Chouchene, B.; Schneider, R.; Wang, W.; Moliere, M.; Liao, H. Tunable morphologies of ZnO films via the solution precursor plasma spray process for improved photocatalytic degradation performance. Appl. Surf. Sci. 2018, 455, 970-979. [CrossRef]

35. Ko, T.S.; Yang, S.; Hsu, H.C.; Chu, C.P.; Lin, H.F.; Liao, S.C.; Lu, T.C.; Kuo, H.C.; Hsieh, W.F.; Wang, S.C. ZnO nanopowders fabricated by dc thermal plasma synthesis. Mater. Sci. Eng. B Solid State Mater. Adv. Technol. 2006, 134, 54-58. [CrossRef]

36. Murali, A.; Sohn, H.Y. Photocatalytic properties of plasma-synthesized zinc oxide and tin-doped zinc oxide (TZO) nanopowders and their applications as transparent conducting films. J. Mater. Sci. Mater. Electron. 2018, 29, 14945-14959. [CrossRef]

37. Lee, B.J.; Jo, S.I.; Jeong, G.H. Synthesis of ZnO Nanomaterials Using Low-Cost Compressed Air as Microwave Plasma Gas at Atmospheric Pressure. Nanomaterials 2019, 9, 942. [CrossRef]

38. Mozetič, M.; Balat-Pichelin, M. Oxidation of $\mathrm{SiC}$ in low-pressure $\mathrm{CO}_{2}$ plasma: Formation of silica nano-needles. Vacuum 2014, 100, 50-52. [CrossRef]

39. Kutasi, K.; Guerra, V.; Paulo, S.A. Theoretical insight into Ar- $\mathrm{O}_{2}$ surface-wave microwave discharges. J. Phys. D Appl. Phys. 2010, 43, 175201. [CrossRef]

40. Šourková, H.; Špatenka, P. Plasma activation of polyethylene powder. Polymers 2020, 12, 2099. [CrossRef] [PubMed]

41. Gosar, Ž.; Kovač, J.; Đonlagić, D.; Pevec, S.; Primc, G.; Junkar, I.; Vesel, A.; Zaplotnik, R. PECVD of Hexamethyldisiloxane Coatings Using Extremely Asymmetric Capacitive RF Discharge. Materials 2020, 13, 2147. [CrossRef] [PubMed]

42. Kylián, O.; Kuzminova, A.; Hanuš, J.; Slavínská, D.; Biederman, H. Super-hydrophilic SiOx coatings prepared by plasma enhanced chemical vapor deposition combined with gas aggregation source of nanoparticles. Mater. Lett. 2018, 227, 5-8. [CrossRef]

43. Košutová, T.; Hanuš, J.; Kylián, O.; Cieslar, M.; Khalakhan, I.; Choukourov, A.; Biederman, H. In-flight coating of Ag nanoparticles with Cu. J. Phys. D Appl. Phys. 2021, 54, 7. [CrossRef]

44. Mozetič, M.; Cvelbar, U.; Sunkara, M.K.; Vaddiraju, S. A method for the rapid synthesis of large quantities of metal oxide nanowires at low temperatures. Adv. Mater. 2005, 17, 2138-2142. [CrossRef]

45. Mozetic, M. Synthesis of metal oxide nanomaterials by plasma treatment-A SEM investigation of $\mathrm{Nb}_{2} \mathrm{O}_{5}$ nanowires. Vacuum 2012, 86, 867-870. [CrossRef] 
46. Sohn, H.Y.; Murali, A. Plasma Synthesis of Advanced Metal Oxide Nanoparticles and Their Applications as Transparent Conducting Oxide Thin Films. Molecules 2021, 26, 1456. [CrossRef] [PubMed]

47. Seo, J.H.; Hong, B.G. Thermal plasma synthesis of nano-sized powders. Nucl. Eng. Technol. 2012, 44, 9-20. [CrossRef]

48. Wallenhorst, L.M.; Loewenthal, L.; Avramidis, G.; Gerhard, C.; Militz, H.; Ohms, G.; Viöl, W. Topographic, optical and chemical properties of zinc particle coatings deposited by means of atmospheric pressure plasma. Appl. Surf. Sci. 2017, 410, 485-493. [CrossRef] 